\title{
Measuring Water Transmission Parameters in Vadose Zone Using Ponded Infiltration Techniques
}

\author{
D.E. Elrick ${ }^{1 *}$ and W.D. Reynolds ${ }^{2}$ \\ ${ }^{1}$ University of Guelph, Guelph, ON, Canada N1G 2W1 \\ ${ }^{2}$ Agriculture and Agri-Food Canada, Harrow, ON, Canada NOR 1 GO
}
قياس خواص نفاذية المياه في التربة غير المشبعة باستخدام تقنيات التسـرب بالغمر ديفد الريك ووليام رينولدس

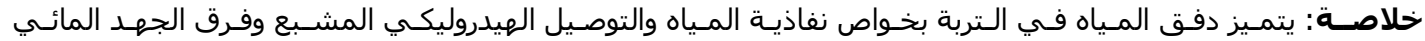

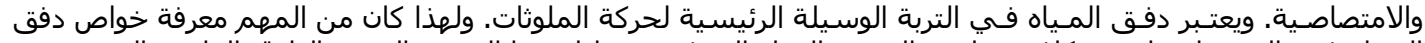

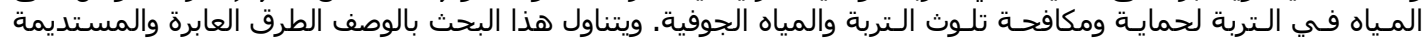

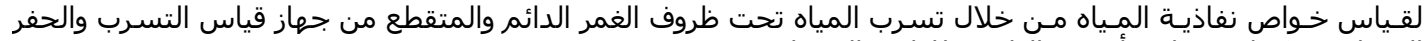

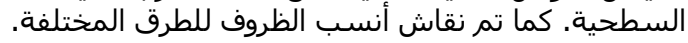

\begin{abstract}
The flow of soil water is characterized by water transmission parameters, field-saturated hydraulic conductivity, matric flux potential and sorptivity. Soil water flow is, in turn, the primary mechanism by which soil contaminants, such as excess plant nutrient, bacteria, viruses, salts, and industrial chemicals are transported. Consequently, knowledge of soil water transmission parameters is essential for understanding, preventing and remediating the contamination of soil water and ground water. This paper describes steady-state and transient methods for obtaining soil water transmission parameters from ponded infiltration under constant head and falling head conditions in surface rings and shallow auger holes. Also discussed are the conditions under which the various methods are most appropriate.
\end{abstract}

Keywords: Vadose, infiltration, ponded, hydraulic conductivity, matric flux, sorptivity, contamination, steady-state, transient, falling head, Darcy's law, unsaturated.

$\mathbf{T}$ The main soil water transmission parameters include the saturated or field-saturated hydraulic conductivity, and the matric flux potential or sorptivity. The saturated/field-saturated hydraulic conductivity characterizes the saturated component of soil water flow, while the matric flux potential or sorptivity characterizes the unsaturated component of flow. In the laboratory, soil water transmission parameters are generally obtained from ponded infiltration measurements made on "undisturbed" soil cores or soil columns extracted from the field. It is much preferred to carry out these measurements in-situ, however, as soil cores and soil columns collected from the field are invariably disturbed to some extent; and perhaps even more importantly, water transmission parameters obtained from isolated soil cores and soil columns may not be adequate representations of the actual field values. In the field, soil water transmission parameters are obtained from infiltration measurements made at the soil surface using constructed ponds or rings, or below the soil surface using shallow bore holes or pits. The infiltration measurements can be made (regardless of whether they are laboratory-based or field-based) under a quasi-steady flow environment or a transient flow environment, and with constant hydraulic head at the infiltration surface or falling (declining) hydraulic head at the infiltration surface. Included below is a brief discussion of water transmission theory and

*Corresponding author. 
parameters, plus descriptions of several techniques for determining water transmission parameters from ponded infiltration measurements.

\section{Water Transmission Theory and Parameters}

The transmission of water through unsaturated soil can be described by Darcy's law:

$$
q=-K(\theta) \frac{\partial H}{\partial z}=-K(\psi) \frac{\partial H}{\partial z}
$$

where

$$
\mathrm{H}=\psi+\mathrm{z}
$$

and $\mathrm{q}\left[\mathrm{L}^{3} \mathrm{~L}^{-2} \mathrm{~T}^{-1}\right]$ is the volume flux density of water (volume of water passing per unit time through a unit cross-sectional area of porous medium perpendicular to the direction of flow), $\partial \mathrm{H} / \partial \mathrm{z}\left[\mathrm{LL}^{-1}\right]$ is the hydraulic head gradient, $K(\theta)\left[\mathrm{LT}^{-1}\right]$ is the hydraulic conductivity $(\mathrm{K})$ versus volumetric water content $(\theta)$ relationship, $\mathrm{K}(\psi)\left[\mathrm{LT}^{-1}\right]$ is the hydraulic conductivity versus pore water pressure head relationship, $\mathrm{H}[\mathrm{L}]$ is hydraulic head, $\psi[\mathrm{L}]$ is pore water pressure head, and $\mathrm{z}[\mathrm{L}]$ is elevation or gravitational head (positive upward).

When the porous medium is saturated,

$$
\mathrm{K}(\theta)=\mathrm{K}(\psi)=\text { constant }=\mathrm{K}_{\mathrm{s}}
$$

where $\mathrm{K}_{\mathrm{s}}\left[\mathrm{LT}^{-1}\right]$ is known as the saturated hydraulic conductivity. The $\mathrm{K}_{\mathrm{s}}$ parameter is highly sensitive to porous medium texture and structure, and as a consequence, its value ranges from as high as $10^{-2}-10^{-4}$ $\mathrm{m} \mathrm{s}^{-1}$ in coarse-textured and/or highly structured or cracked soils, to as low as $10^{-8}-10^{-10} \mathrm{~m} \mathrm{~s}^{-1}$ in compacted, structureless clay soils and landfill liners. When hydraulic conductivity is measured via ponded infiltration into initially unsaturated soil, it is often referred to as the "field-saturated" hydraulic conductivity, $\mathrm{K}_{\mathrm{fs}}$, as some amount of air is usually entrapped in the soil by the infiltrating water. This can result in $\mathrm{K}_{\mathrm{fs}} \leq \mathrm{K}_{\mathrm{s}}$, but it is often argued that $\mathrm{K}_{\mathrm{fs}}$ is more appropriate than $\mathrm{K}_{\mathrm{s}}$ because most natural and manmade infiltration processes result in entrapment of air in the soil.

Ponded infiltration $(\psi \geq 0)$ into initially unsaturated soil is affected not only by $\mathrm{K}_{\mathrm{fs}}$, but also by one of several parameters that derive from the $\mathrm{K}(\psi)$ relationship. To illustrate this, we can conveniently use the empirical $\mathrm{K}(\psi)$ function of Gardner (1958):

$$
\begin{gathered}
\mathrm{K}(\psi)=\mathrm{K}_{\mathrm{fs}} \exp \left[\alpha\left(\psi-\psi_{\mathrm{e}}\right)\right] ; 0<\alpha<+\vartheta ; \psi<\psi_{\mathrm{e}} \leq 0 \\
\mathrm{~K}(\psi)=\mathrm{K}_{\mathrm{fs}} ; \psi \geq \psi_{\mathrm{e}}
\end{gathered}
$$

where $\alpha\left[\mathrm{L}^{-1}\right]$ is a slope parameter that depends primarily on soil texture and structure, and $\psi_{\mathrm{e}}[\mathrm{L}]$ is the air-entry or water-entry pressure head, depending on whether the soil is draining or wetting, respectively. Integrating (4a) between $\psi=\psi_{\mathrm{i}}$ and $\psi=\psi_{\mathrm{e}}$ produces,

$$
\phi_{\mathrm{m}}=\int_{\psi_{\mathrm{i}}}^{\psi_{\mathrm{e}}} \mathrm{K}\left(\psi(\psi)=\frac{\mathrm{K}_{\mathrm{s}}-\mathrm{K}_{\mathrm{i}}}{\alpha} \approx \frac{\mathrm{K}_{\mathrm{s}}}{\alpha^{*}}\right.
$$

where $\phi_{\mathrm{m}}\left[\mathrm{L}^{2} \mathrm{~T}^{-1}\right]$ is the matric flux potential, $\psi_{\mathrm{i}}[\mathrm{L}]$ is the initial or background pore water pressure head in the unsaturated porous medium, and $\mathrm{K}_{\mathrm{i}}\left[\mathrm{LT}^{-1}\right]$ is the initial or background hydraulic conductivity corresponding to $\psi_{\mathrm{i}}$. The $\phi_{\mathrm{m}}$ parameter is an indicator of the capillary pull or "capillarity" exerted by the unsaturated porous medium on the water during an infiltration or drainage process. Under saturated conditions, $\phi_{\mathrm{m}}=0$ because $\mathrm{K}_{\mathrm{i}}=\mathrm{K}_{\mathrm{s}}$ in (5).

In most natural unsaturated soils we can assume that:

$$
\alpha \approx \alpha^{*} \equiv \frac{\mathrm{K}_{\mathrm{fs}}}{\varphi_{\mathrm{m}}}=-\frac{1}{\psi_{\mathrm{f}}}=\left|\frac{1}{\psi_{\mathrm{f}}}\right|
$$

where the macroscopic capillary length parameter, $\alpha^{*}$ $\left[\mathrm{L}^{-1}\right]$, represents the ratio of gravity to capillarity forces during infiltration or drainage and $\psi_{\mathrm{f}}[\mathrm{L}]$ (negative in value) represents the effective wetting front pressure head of the Green-Ampt infiltration model (Green and Ampt, 1911). Large $\alpha^{*}$ values indicate dominance of gravity over capillarity, which occurs primarily in coarse textured and/or highly structured porous media. Small $\alpha^{*}$ on the other hand, indicate dominance of capillarity over gravity, which occurs primarily in fine textured and/or unstructured porous media. Although, $\mathrm{K}_{\mathrm{fs}}$ and $\phi_{\mathrm{m}}$ can individually range over many orders of magnitude in a porous medium, $\alpha^{*}$ generally varies from about $0.01 \mathrm{~cm}^{-1}$ to $0.5 \mathrm{~cm}^{-1}$. The reduced variability of $\alpha^{*}$, along with its connection to porous medium texture and structure, make it a useful parameter in simplified single-head analyses for estimation of $\mathrm{K}_{\mathrm{fs}}$ and $\phi_{\mathrm{m}}$ in unsaturated porous media (discussed further below, and in Reynolds et al., 2002).

Sorptivity ( $\mathrm{S}$ ) is a measure of the ability of an unsaturated porous medium to absorb or store water as a result of capillarity. The $S$ and $\phi_{\mathrm{m}}$ parameters are related by (White and Sully, 1987):

$$
\mathrm{S}_{\mathrm{H}}=\left\{\frac{(\Delta \theta) \phi_{\mathrm{m}}}{\mathrm{b}}+2(\Delta \theta) \mathrm{K}_{\mathrm{fs}} \mathrm{H}\right\}^{1 / 2}
$$

where $\Delta \theta=\left(\theta_{\mathrm{fs}}-\theta_{\mathrm{i}}\right), \theta_{\mathrm{fs}}\left(\mathrm{L}^{3} \mathrm{~L}^{-3}\right)$ is the field-saturated volumetric soil water content, $\theta_{\mathrm{i}}\left(\mathrm{L}^{3} \mathrm{~L}^{-3}\right)$ is the initial volumetric soil water content, $\mathrm{b}$ is a dimensionless empirical constant, and $\mathrm{H}$ is the applied constant head 


\section{MEASURING WATER TRANSMISSION PARAMETERS IN VADOSE ZONE USING PONDED INFILTRATION TECHNIQUES}

of water. Setting $b=0.55$ for infiltration gives an error of less than $10 \%$ in $\mathrm{S}_{\mathrm{H}}$. The first term in (7) gives the sorptivity, $\mathrm{S}_{0}$, for $\mathrm{H}=0$ and the second term gives the increase in sorptivity due to the positive (ponded) head, H. Note that either $\phi_{\mathrm{m}}$ or $\mathrm{S}$ or $\alpha^{*}$ are needed along with $\mathrm{K}_{\mathrm{fs}}$ to predict and characterize ponded infiltration into unsaturated porous media. Note also that under saturated conditions, $S_{\mathrm{H}}=0$ because $\Delta \theta=0$ in (7) (i.e. $\theta_{\mathrm{i}}=\theta_{\mathrm{fs}}$ ).

\section{Determining Water Transmission Parameters from Ponded Infiltration}

We will use the following terms to describe the infiltration process:

$$
\mathrm{q}_{\mathrm{z}=0}=\mathrm{i}=\frac{\mathrm{dI}}{\mathrm{dt}}=\frac{1}{\mathrm{~A}} \frac{\mathrm{dQ}}{\mathrm{dt}}
$$

where $\mathrm{i}\left(\mathrm{LT}^{-1}\right)$ is the infiltration rate, $\mathrm{I}(\mathrm{L})$ is the cumulative infiltration, A $\left(\mathrm{L}^{2}\right)$ is the cross-sectional area through which water is flowing and $\mathrm{Q}\left(\mathrm{L}^{3} \mathrm{~T}^{-1}\right)$ is the volumetric intake rate (recharge) of water.

\section{PONDED INFILTRATION FROM A SINGLE RING:}

\section{Constant Head Methods}

\section{i) One-Dimensional flow assumption - transient flow}

One of the earliest expressions used to describe infiltration, which includes sorption and gravity, was derived by Green and Ampt (1911):

$$
\mathrm{t}=\frac{(\Delta \theta)}{\mathrm{CK}_{\mathrm{fs}}}\left[\frac{\mathrm{I}(\mathrm{t})}{\Delta \theta}-\frac{\left(\mathrm{H}+\frac{1}{\alpha^{*}}\right)}{\mathrm{C}} \ln \left(1+\frac{\mathrm{CI}(\mathrm{t})}{(\Delta \theta)\left(\mathrm{H}+\frac{1}{\alpha^{*}}\right)}\right)\right]
$$

where $\mathrm{C}=1$.

Philip $(1957,1958)$ showed that one-dimensional infiltration can be described by:

$$
I(t)=S_{H^{1 / 2}}
$$

if gravity is neglected, and by:

$$
I(t)=S_{H} t^{1 / 2}+A t
$$

if gravity is included. The A parameter ranges in value from 0 for early time infiltration, to approximately $\mathrm{K}_{\mathrm{fs}} / 3$ for intermediate time infiltration, to $\mathrm{K}_{\mathrm{fs}}$ at steady state (long time infiltration). ii) One-Dimensional flow assumption - steady-state flow Green and Ampt (1911) give the following expression:

$$
\mathrm{i}=\mathrm{K}_{\mathrm{fs}}\left[\left(\frac{\mathrm{H}+\frac{1}{\alpha^{*}}}{\mathrm{~L}_{\mathrm{f}}}\right)+1\right]
$$

where $\mathrm{L}_{\mathrm{f}}$ is the distance from the infiltration surface to the wetting front. At large time, steady-state is approached because $\mathrm{L}_{\mathrm{f}}$ in the denominator of (12) becomes large relative to the numerator, and consequently $\mathrm{i} \rightarrow \mathrm{K}_{\mathrm{fs}}$.

\section{iii) Three-Dimensional flow assumption - transient flow}

Numerical methods are generally used to determine 3D transient flow. However, at early times before 3D flow significantly affects $I(t)$, equations (9),(10) and (11) can be used as approximations.

\section{iv) Three-Dimensional flow assumption - steady-state flow}

Steady state infiltration through a ring infiltrometer can be described by (Reynolds and Elrick, 1990):

$$
\mathrm{i}=\frac{\mathrm{Q}}{\mathrm{A}}=\mathrm{K}_{\mathrm{fs}}\left[\left[\frac{\mathrm{H}}{\mathrm{C}_{1} \mathrm{~d}+\mathrm{C}_{2} \mathrm{a}}+\frac{1}{\alpha^{*}\left(\mathrm{C}_{1} \mathrm{~d}+\mathrm{C}_{2} \mathrm{a}\right)}\right]+1\right]
$$

where $\mathrm{H}[\mathrm{L}]$ is the constant depth of ponded water in the ring, $d[\mathrm{~L}]$ is the depth of ring insertion into the soil and $\mathrm{a}[\mathrm{L}]$ is the radius of the ring. The parameters, $\mathrm{C}_{1}=$ $0.316 \pi$ and $C_{2}=0.184 \pi$ are dimensionless constants which apply for $\mathrm{d} \geq 3 \mathrm{~cm}$ and $\mathrm{H} \geq 5 \mathrm{~cm}$.

\section{Falling Head Methods}

Under falling head conditions the head, $\mathrm{H}(\mathrm{t})$, decreases with time, t. If $\mathrm{H}(0)=\mathrm{D}$, the cumulative infiltration, $I(t)$, can then be obtained experimentally from:

$$
I(t)=R[D-H(t)]
$$

where $\mathrm{R}=\mathrm{a} / \mathrm{A}$ is the ratio of the cross sectional area of the falling head reservoir, a, to the cross-sectional area of the infiltrating surface, A. Obviously, there are no steady-state solutions for falling head conditions, and falling head solutions are valid only for $0 \leq \mathrm{I} \leq \mathrm{RD}$.

\section{i) One-Dimensional flow assumption - transient flow}

Elrick et al. (2002) give the following expression for $I(t)$ when gravity effects are ignored: 


$$
\mathrm{t}=-\frac{\mathrm{R}}{\mathrm{K}_{\mathrm{fs}}(\Delta \theta)}\left[\mathrm{I}(\mathrm{t})+\mathrm{B}(\Delta \theta) \ln \left(1-\frac{\mathrm{I}(\mathrm{t})}{\mathrm{B}(\Delta \theta)}\right)\right]
$$

where $\mathrm{B}=\mathrm{R}\left(\mathrm{D}-\Psi_{\mathrm{f}}\right) / \Delta \theta$. The corresponding equation which includes gravity was derived by Philip (1992) and is given by $(9)$ where $C=1-(\Delta \theta) / R$.

\section{ii) Three-Dimensional flow assumption - transient flow}

Numerical methods are generally used to determine 3D transient flow under falling head conditions. However, at early times before 3D flow significantly affects $I(t)$, equations (9),(10) and (11) can be used as approximations.

\section{PONDED INFILTRATION FROM AN AUGER HOLE:}

\section{Constant Head Methods}

i) One-Dimensional flow assumption - transient flow No valid approximation available.

ii) One-Dimensional flow assumption - steady-state flow Porchet and Laferrere (1935) give the following solution:

$$
\mathrm{Q}=\mathrm{K}_{\mathrm{fs}}\left(\pi \mathrm{a}^{2}+2 \pi \mathrm{aH}\right)
$$

Equation (16) is an early attempt to measure $K_{\mathrm{fs}}$ and assumes both saturated conditions throughout the soil profile and a unit gradient (which is equivalent to gravity flow) across the combined areas of the auger hole bottom $\left(\pi \mathrm{a}^{2}\right)$ and submerged portion of the auger hole wall $(2 \pi \mathrm{aH})$. These gross approximations can lead to errors in $\mathrm{K}_{\mathrm{fs}}$ ranging from as little as a factor of 2 to more than a factor of 10 .

\section{iii) Three-Dimensional flow assumption - transient flow}

Analyses are complex and difficult to apply as they require the use of numerical models.

\section{iv) Three-Dimensional flow assumption - steady-state flow}

Over the past 75 years there have been a number of approximate analytical solutions, but it was only about 20 years ago that the unsaturated component was first taken into account (Stevens and Neuman, 1982; Reynolds et al., 1983). Reynolds and Elrick (1987) give the following expression:

$$
\mathrm{Q}=\mathrm{K}_{\mathrm{fs}}\left(\frac{2 \pi \mathrm{H}^{2}}{\mathrm{C}}+\frac{2 \pi \mathrm{H}}{\mathrm{C} \alpha^{*}}+\pi \mathrm{a}^{2}\right)
$$

where the terms on the right hand side represent the respective contributions of pressure, capillarity and gravity. The dimensionless shape factor, C, was obtained from numerical calculations.

\section{Falling Head Methods}

One of the simplest experimental procedures is to measure the rate of fall of water in an auger hole. That is probably why the percolation test (generally referred to as the "Perc" test) has been used for over 75 years to determine site suitability for in-ground wastewater treatment facilities such as septic systems. This test has traditionally measured only the time required for water to fall a pre-set distance ("T-time") and has not been used to calculate $\mathrm{K}_{\mathrm{fs}}$.

\section{i) One-Dimensional flow assumption}

No valid approximation available.

\section{ii) Three-Dimensional flow assumption}

An approximate solution, based on the assumption of a series of steady state solutions, can be obtained by rewriting (17) as (Elrick and Reynolds, 1986):

$$
\mathrm{t}=\mathrm{a}^{2} \int_{\mathrm{H}}^{\mathrm{D}} \frac{\mathrm{CdH}}{\mathrm{K}_{\mathrm{fs}}\left(2 \mathrm{H}^{2}+\mathrm{a}^{2} \mathrm{C}+\frac{2 \mathrm{H}}{\alpha^{*}}\right)}
$$

where $t$ is the time required for the water to fall from the initial height $\mathrm{H}=\mathrm{D}$ to a given height $\mathrm{H}=\mathrm{H}$. Equation (18) needs to be integrated numerically, and steady constant head infiltration should be obtained at $\mathrm{H}=\mathrm{D}$ before the falling head phase is started.

Philip (1993) developed a solution for the falling head permeameter where the sides of the auger hole are lined and thus water infiltrates only from the base of the auger hole:

$$
\mathrm{t}(\mathrm{H})=\frac{\pi^{2} \mathrm{r}}{8 \mathrm{~K}_{\mathrm{fs}}}\left[\begin{array}{l}
\left.\left(1+\frac{1}{2 \mathrm{~A}}\right) \ln \left(\frac{\mathrm{A}^{3}-1}{\mathrm{~A}^{3}-\rho^{3}}\right)-\frac{3}{2 \mathrm{~A}} \ln \left(\frac{\mathrm{A}-1}{\mathrm{~A}-\rho}\right)+\right] \\
\frac{\sqrt{3}}{\mathrm{~A}}\left[\arctan \left(\frac{\mathrm{A}+2 \rho}{\sqrt{3} \mathrm{~A}}\right)-\arctan \left(\frac{\mathrm{A}+2}{\sqrt{3} \mathrm{~A}}\right)\right]
\end{array}\right]
$$

where A and $\rho$ are given by (24). See Philip (1993) and Munoz-Carpena et al. (2002) for details.

\section{Discussion}

Although the analyses described above are only a small fraction of the total number available, they are among the most widely tested and most frequently used. The best choice of methodology and analysis depends to some extent on the nature of the soil (e.g., low or high permeability) and on your objective. For example, medium and high permeability soils (e.g., $\mathrm{K}_{\mathrm{fs}}>10^{-6} \mathrm{~m} \mathrm{~s}^{-1}$ ) permit the use of relatively simple constant head procedures 


\section{MEASURING WATER TRANSMISSION PARAMETERS IN VADOSE ZONE USING PONDED INFILTRATION TECHNIQUES}

with small ponded heads, and usually require less than an hour to obtain a measurement. On the other hand, low conductivity soils (e.g., $\mathrm{K}_{\mathrm{fs}}<10^{-7} \mathrm{~ms}^{-1}$ ) are more of a challenge, often requiring a higher ponded head and the use of more complex early-time, falling head techniques. In addition, the "best" technology will differ depending on whether your objective is, for example, to intensively characterize a small, easily accessible area, or to conduct a broad survey in a remote area where simple portable equipment and low water usage are essential.

Measurements at or near the soil surface (e.g., < $0.5 \mathrm{~m}$ depth) should probably be made using a single ring method such as the pressure infiltrometer. At greater depths (e.g., $>0.5 \mathrm{~m}$ ) a well permeameter is probably the best approach. Constant and falling head techniques can be used with both the ring and well permeameter techniques; however, we recommend use of the pressure infiltrometer whenever possible because of its procedural and analytical advantages over the well permeameter. Further detail on collecting and interpreting pressure infiltrometer and well permeameter data can be found in Reynolds et al. (2002).

DETAILED RESEARCH INVESTIGATIONS: Detailed research investigations might require information on both the saturated and unsaturated components of $\mathrm{K}(\psi)$. Constant head analyses for single ring pressure infiltrometers or well permeameters can be used for moderate to high conductivity soils $\left(>10^{-6} \mathrm{~m} \mathrm{~s}^{-1}\right)$. Two or more heads $\left(\mathrm{H}_{1}, \mathrm{H}_{2}, \mathrm{H}_{3}, \ldots\right)$ can be applied to obtain two or more steady state intake rates $\left(\mathrm{Q}_{1}, \mathrm{Q}_{2}, \mathrm{Q}_{3}, \ldots\right)$ and (13) or (17) can be solved for $\mathrm{K}_{\mathrm{fs}}$ and $\phi_{\mathrm{m}}$ (or $\alpha^{*}$ ). See Reynolds et al. (2002) for details on procedures and calculations using the two-head or multiple-head analyses. If the soil properties change considerably within the measurement zone, or if $\mathrm{Q}_{\mathrm{i}}$ is measured inaccurately, an unrealistic (e.g., negative) value can be obtained for either $\mathrm{K}_{\mathrm{fs}}$ or $\phi_{\mathrm{m}}$. This simply means that the two-head or multiple-head approach was inappropriate for this site and the next step is to apply the updated single-head approach to each individual head measurement for which $\alpha^{*}$ is either estimated or measured independently (Reynolds et al. 2002). The individual results can then be averaged to obtain overall $\mathrm{K}_{\mathrm{fs}}$ and $\phi_{\mathrm{m}}\left(\right.$ or $\left.\alpha^{*}\right)$ values.

Early-time constant head and falling head techniques can also be used for medium and low conductivity soils. For constant head procedures see Elrick and Reynolds (1992) and Vauclin et al. (1994). For falling head procedures see Elrick et al. (1995, 2002).
APPLIED ENGINEERING INVESTIGATIONS: Applied engineering investigations often require only "ball park" estimates of $\mathrm{K}_{\mathrm{fs}}$. In this case, procedures using a single, constant head can be used where $\alpha^{*}$ is either estimated or measured independently. The $\mathrm{K}_{\mathrm{fs}}$ value can then be obtained from:

Pressure infiltrometer:

$$
\mathrm{K}_{\mathrm{fs}}=\frac{\alpha^{*} \mathrm{GQ}}{\mathrm{a}\left(\alpha^{*} \mathrm{H}+1\right)+\mathrm{Ga}{ }^{*} \pi \mathrm{a}^{2}}
$$

Well permeameter:

$$
\mathrm{K}_{\mathrm{fs}}=\frac{\mathrm{CQ}}{2 \pi \mathrm{H}^{2}+\mathrm{C} \pi \mathrm{a}^{2}+\frac{2 \pi \mathrm{H}}{\alpha^{*}}}
$$

Note that $G=0.316 \mathrm{~d} / \mathrm{a}+0.184$, where $d$ is the depth of insertion of the ring and $\mathrm{a}$ is the radius of the ring. The shape factor, $\mathrm{C}$, is determined from a curve of $\mathrm{C}$ vs. $\mathrm{H} / \mathrm{a}$ (Reynolds et al. 2002) or from empirical expressions (Zhang, 1998). Tables for estimating $\alpha^{*}$ are given in Reynolds et al.. (2002).

SURVEY INVESTIGATIONS - EXTENSIVE DATA COLLECTION: If portability of equipment and water conservation are essential, or if funds, time or labour are severely restricted, simplified falling head techniques for both ring and well permeameters may be an option. For example, Bagarello et al. (submitted) proposed a simplified falling head pressure infiltrometer analysis of the form:

$\mathrm{K}_{\mathrm{fs}}=\frac{\Delta \theta}{\mathrm{t}(1-\Delta \theta)}\left[\frac{\mathrm{D}}{\Delta \theta}-\frac{\mathrm{D}+\frac{1}{\alpha^{*}}}{1-\Delta \theta} \ln \left\{1+\frac{\mathrm{D}(1-\Delta \theta)}{\Delta \theta\left(\mathrm{D}+\frac{1}{\alpha^{*}}\right)}\right\}\right]$

while Munoz-Carpena et al. (2002) developed a simplified analysis for a lined well permeameter open only at the base:

$$
\mathrm{K}_{\mathrm{fs}}=\frac{\pi^{2} \mathrm{r}}{8 \mathrm{t}}\left[\begin{array}{l}
\left(1+\frac{1}{2 \mathrm{~A}}\right) \ln \left(\frac{\mathrm{A}^{3}-1}{\mathrm{~A}^{3}-\rho^{3}}\right)-\frac{3}{2 \mathrm{~A}} \ln \left(\frac{\mathrm{A}-1}{\mathrm{~A}-\rho}\right)+ \\
\frac{\sqrt{3}}{\mathrm{~A}}\left[\arctan \left(\frac{\mathrm{A}+2 \rho}{\sqrt{3} \mathrm{~A}}\right)-\arctan \left(\frac{\mathrm{A}+2}{\sqrt{3} \mathrm{~A}}\right)\right]
\end{array}\right]
$$




\section{ELRICK AND REYNOLDS}

where

$$
\begin{gathered}
\mathrm{A}^{3}=\frac{3\left(\mathrm{D}+\frac{1}{\alpha^{*}}+\frac{\pi \mathrm{a}^{2}}{8}\right)}{\mathrm{a}(\Delta \theta)}+1 \\
\rho^{3}=1+\frac{3 \mathrm{D}}{\mathrm{a}(\Delta \theta)}
\end{gathered}
$$

If $\alpha^{*}$ is estimated or determined independently, then $\mathrm{K}_{\mathrm{fs}}$ can be obtained directly from either of the above equations. In both (22) and (23), $t$ is the time required for the water level to drop from its initial maximum height, D, to either the soil surface (pressure infiltrometer) or the bottom of the well (well permeameter). The procedure of Munoz-Carpena et al. (2002) has been simplified to a single measurement. It should be remembered, however, that these simplified and largely untested solutions may be of reduced accuracy relative to the other methods.

\section{References}

Bagarello, V., M. Iovino, and D.E. Elrick. 2002. A simplified fallinghead technique for rapid determination of field-saturated hydraulic conductivity. Submitted to Soil Sci. Soc. Am. J.

Elrick, D.E. and W.D. Reynolds. 1986. An analysis of the percolation test based on three-dimensional, saturated-unsaturated flow from a cylindrical test hole. Soil Sci. 142:308-321.

Elrick, D.E. and W.D. Reynolds. 1992. Infiltration from constant head well permeameters and infiltrometers. In Measurement of Soil Physical Properties: Bringing Theory into Practice. G.C. Topp and R.E. Green, Ed. Soil Sci. Soc. Am., Madison, WI Spec. Pub. 30, pp 1-24.

Elrick, D.E., G.W. Parkin, W.D. Reynolds and D.J. Fallow. 1995. Analysis of early-time and steady-state single ring infiltration under falling head conditions. Water Resour. Res. 31:1883-1893.

Elrick, D.E., R. Angulo-Jaramillo, D.J. Fallow, W.D. Reynolds, and G.W. Parkin. 2002. Infiltration under constant head and falling head conditions in "Environmental Mechanics: Water, Mass and Energy Transfer in the Biosphere", Ed. by Raats, Smiles and Warrick, Geophysical Monograph Series Vol. 129, AGU Washington, D.C., pp 47-53.
Gardner, W.R. 1958. Some steady-state solutions of the unsaturated moisture flow equation with application to evaporation from a water table. Soil Sci., 85:228-232.

Green, W.H. and G.A. Ampt, 1911. Studies in soil physics. I. The flow of air and water through soils. J. Agr. Sci. 4, 1-24.

Munoz-Carpena, R., C.M. Regalado, J. Alvarez-Benedi, and F. Bartoli. 2002. Field evaluation of the new Philip-Dunne Permeameter for measuring saturated hydraulic conductivity. Soil Science 167:9- 24.

Philip, J.R. 1957. The theory of infiltration: 4, Sorptivity and the algebraic infiltration equation., Soil Sci 84:329-339.

Philip, J.R. 1958. The theory of infiltration: 6, Effect of water depth over soil. Soil Sci. 84: 329-339.

Philip, J.R. 1992. Falling head ponded infiltration, Water Resour. Res. 28: 2147-2148.

Philip, J.R. 1993. Approximate analysis of falling-head lined borehole permeameter. Water Resour. Res. 29: 3763-3768.

Porchet, M. and H. Laferrere. 1935. Determination des characteristiques hydrodynamiques des sols en place. Ch. IV. Annal. Mem. Notes Techniques 64: 5-68.

Reynolds, W.D., D.E. Elrick, and G.C. Topp. 1983. A reexamination of the constant head well permeameter method for measuring saturated hydraulic conductivity above the water table. Soil Science 136:250-268.

Reynolds, W.D. and D.E. Elrick. 1987. A laboratory and numerical assessment of the Guelph Permeameter method. Soil Science 144:282-299.

Reynolds, W.D. and D.E. Elrick. 1990. Ponded infiltration from a single ring: I. Analysis of steady flow. Soil Sci. Soc. Am. J. 54: 1233-1241.

Reynolds, W.D., D.E. Elrick, E.G. Youngs, A. Amoozegar, H.W.G. Booltink, and J. Bouma. 2002. Ch. 3.4, Saturated and fieldsaturated water flow parameters, in Methods of Soil Analysis, Part 4. Physical Methods, J. Dane and C. Topp, Ed., 82p.

Stevens, D.B. and S.P. Neuman. 1982. Vadose zone permeability tests. ASCE J. Hydraul. Div. 108:640-659.

Vauclin, M., D.E. Elrick, J.L. Thony, G. Vachaud, Ph. Revol, and P. Ruella. 1994. Hydraulic conductivity measurements of the spatial variability of a loamy soil. Soil Tech. 7: 181-195.

White, I. and M.J. Sully. 1987. Macroscopic and microscopic capillary length and time scales from field infiltration. Water Resour. Res. 23:1514-1522.

Zhang, Z.F., P.H. Groenevelt, and G.W. Parkin. 1998. The well shape-factor for the measurement of soil hydraulic properties using the Guelph Permeameter. Soil Tillage Res. 49:219-221.

Received March 2002

Accepted November 2002 